\title{
Color vision deficiency among biomedical students: a cross-sectional study
}

This article was published in the following Dove Press journal: Clinical Ophthalmology

\author{
Viola Andin Dohvoma \\ Stève Robert Ebana Mvogo \\ Giles Kagmeni \\ Nathalie Rosine Emini \\ Emilienne Epee \\ Côme Ebana Mrogo
}

Department of Ophthalmology and ENT, Faculty of Medicine and Biomedical Sciences, University of Yaoundé I, Yaoundé, Cameroon

Correspondence: Viola Andin Dohvoma Faculty of Medicine and Biomedical Sciences, University of Yaoundé I, PO Box 385I Messa, Yaoundé,

Cameroon

Tel +237699735506

Email andinv@gmail.com
Purpose: To determine the prevalence of color vision deficiency (CVD) among first-cycle students of the Faculty of Medicine and Biomedical Sciences of the University of Yaoundé I. Patients and methods: A cross-sectional descriptive study was carried out between October 1, 2015 and May 31, 2016. Distant visual acuity was measured and color vision test done for all consenting students. Ishihara's plates were used to test all the participants. Those who failed the test were tested with the Roth's 28 Hue test for confirmation of CVD and classification.

Results: A total of 303 students were included, among whom 155 were males $(50.8 \%)$ and 148 were females $(49.2 \%)$. The mean age was $20.2 \pm 2$ years. Five students $(1.6 \%)$ failed the Ishihara's plate testing. Roth's 28 Hue test confirmed CVD in 4 of those cases, giving a prevalence of $1.3 \%$. There were equal numbers of protan and deutan CVD.

Conclusion: Despite its low prevalence among first-cycle students of the Faculty of Medicine and Biomedical Sciences, CVD screening should be performed in order to raise awareness, which will go a long way to help orientate the choice of future specialty.

Keywords: color vision deficiency, deutan, protan, biomedical students

\section{Introduction}

Color vision deficiency (CVD) is a condition characterized by disturbances of color perception that occurs if the amount of visual pigment per cone is reduced or if 1 or more of the 3 cone systems are absent. Normal vision is trichromatic. Dichromats have 2 , instead of the normal 3 cone photopigments. Anomalous trichromats have 3 , usually only 1 of which is abnormal. CVDs are either congenital or acquired. The transmission of congenital red-green deficiencies (protan and deutan) is X-linked recessive $^{1}$ and that of blue deficiency (tritan) is autosomal dominant. ${ }^{2}$ Congenital tritan deficiency is a rare entity. ${ }^{3}$ The prevalence of CVD in European Caucasians is about $8 \%$ in men and $0.4 \%$ in women. ${ }^{4}$ A study among school children in our setting found a prevalence of $4.28 \% .^{5}$ Variations exist among different ethnic populations.

Color vision plays an important role in health care, as some medical signs are based on changes in color. Medical doctors with CVD can find difficulties in their practice. ${ }^{6}$ These difficulties include identifying signs such as pallor, jaundice, and red rashes. ${ }^{7}$ There is, therefore, a risk in patient safety from possible diagnostic errors. The ability to identify and outline colored clinical signs has also been shown to be significantly less in practitioners with CVD compared with those without CVD. ${ }^{8}$ Color vision is also important in dentistry for color and shade selection in the field of esthetic restorative dentistry. Color-defective dental personnel make significantly greater errors than color-vision normal dental personnel. ${ }^{9}$ 
Medical students with CVD have been shown to have more problems in interpreting color-dependent clinical and laboratory photographs. ${ }^{8,10}$ This may lead to difficulties in learning histology, pathology, hematology, microbiology, dermatology, pediatrics, medicine, and ophthalmology. Such difficulties may lead to failure in examination and difficulty in medical practice later on.

Most of the time, people with CVD are unaware of their deficiency. Physicians who are aware of their deficiency report taking special care in clinical practice by devising strategies to overcome their disability. ${ }^{7}$ Patel et al ${ }^{11}$ reported a prevalence of CVD of $1.8 \%$ among medical students in India, while Pramanik et al ${ }^{12}$ reported a prevalence of $5.58 \%$ among health science students in Nepal. To the best of our knowledge, no such study has been carried out in our setting. The aim of this study was to determine the prevalence of CVD among first-cycle students of the Faculty of Medicine and Biomedical Sciences (FMBS) of University of Yaoundé 1, in order to raise awareness in those with CVD. Awareness of CVD will lead to a reduction in anxiety during learning and may guide in choice of specialty.

\section{Patients and methods}

We carried out a cross-sectional and descriptive study between October 1, 2015 and May 31, 2016. Our study was reviewed and approved by the Institutional Ethical Clearance Committee of the FMBS of the University of Yaoundé I. Written informed consent was obtained from all participants. Sampling was consecutive and exhaustive.

Participants were first-cycle students of the FMBS who were enrolled into medicine, dentistry, and pharmacy courses for the 2015/2016 academic year following a competitive entrance examination. A self-filled questionnaire was given to the participants to obtain sociodemographic data and past history. Distant visual acuity was measured. Those who had used medications that are potentially toxic for the retina or the optic nerve and those with a visual acuity of $<0.2$ were excluded. The Ishihara 38 plate edition was used for screening CVD. If a participant missed the demonstration plate, the test was discontinued. Plates 2-21 were used for screening red-green defects, and plates $22-25$ were for protan and deutan classification.

The participant was instructed to read the numbers in each plate within 3 seconds. The plates were held at a distance of 75 $\mathrm{cm}$ perpendicular to the line of sight under daylight illumination. A pass of the Ishihara test was the ability to read all plates correctly or an incorrect response in 3 or less plates. Those with 4 or more errors performed the Roth's 28 Hue test for confirmation and differentiation of dichromats from anomalous trichromats. Each participant had to arrange the 27 caps in a circular sequence with respect to the fixed reference cap. They were allowed to alter the sequence prior to completion, and the test was to be completed in a maximum of 10 minutes. Scoring was accomplished by plotting the order of the caps on the diagram showing correct cap positions on the score sheet. Lines connecting the caps in their actual order were drawn.

If the lines remained along the circumference of the circle, the participant was deemed to be "normal". If the sequence lines crossed the center repeatedly, the patient had a CVD. The type of defect was determined by comparing these crossover lines to see if they were parallel to the known color confusion axes. Considering the similarity between the Roth 28 Hue test and the Fansworth D-5 test, those with at least 6 crossover lines were considered dichromats. ${ }^{13}$

\section{Results}

Among the 303 students enrolled and tested, there were 155 males (50.8\%) and 148 females (49.2\%). The mean age was $20.2 \pm 2$ years. Most of them were Cameroonians (99.3\%; $\mathrm{n}=301)$. There were only 2 foreigners: 1 Chadian and 1 Rwandan. Students enrolled in medicine were the most represented $(50.5 \% ; \mathrm{n}=153)$. Those enrolled in dentistry and pharmacy represented $33.7 \%$ and $15.8 \%$, respectively.

Five students (1.7\%), all of them Cameroonians, had 4 or more errors on the Ishihara screening test. All of them were males (Table 1). These students were tested using the Roth 28 test. One was normal, and 4 were confirmed with CVD (Figure 1), giving a prevalence of $1.3 \%(95 \% \mathrm{CI}$ : 0.0051-0.0334). Two were deutans and 2 were protans. No case of total color blindness was detected. The prevalence was $1.96 \%(n=3 / 153)$ among medical students and $0.98 \%$ $(n=1 / 102)$ among dentistry students. No case of CVD was found $(n=0 / 48)$ among pharmacy students. None of them were conscious of difficulties in identifying colors and none had ever taken a color vision test before.

\section{Discussion}

The prevalence of CVD varies depending on race and ethnicity. The prevalence in this study is similar to that reported by Patel et $\mathrm{al}^{11}$ in medical students in India; $1.8 \%$. A higher prevalence

Table I Distribution of the Ishihara test results according to sex

\begin{tabular}{lll}
\hline Sex & Normal, $\mathbf{n}(\%)$ & Abnormal, $\mathbf{n}(\%)$ \\
\hline Male & $150(49.5)$ & $5(1.7)$ \\
Female & $148(48.8)$ & $0(0.0)$ \\
Total & $298(98.3)$ & $5(1.7)$ \\
\hline
\end{tabular}




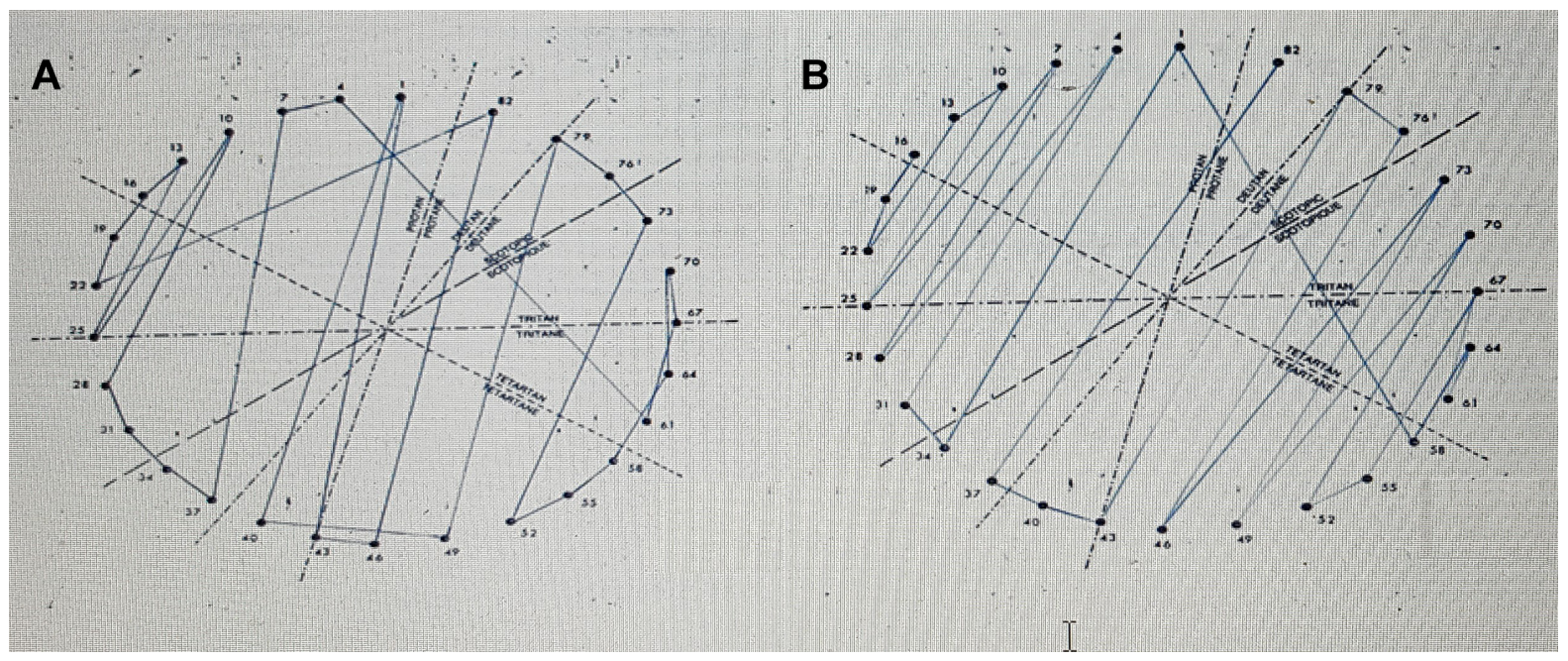

Figure I Scoring in Roth 28 Hue test showing protan (A) and deutan (B) deficiencies.

of $5.58 \%$ was reported in Nepal among male medical and dental students. ${ }^{12}$ This can be attributed to racial differences in the prevalence of CVDs. Higher prevalences are documented among other races compared with African populations. ${ }^{4}$

Red-green perceptive disorders are X-linked recessive, and thus are seen more frequently in males than in females. ${ }^{11}$ No case of CVD in a female was found in our study. Mughal et a ${ }^{14}$ in Pakistan reported a higher prevalence among female students. They concluded that more research is needed to explore the problem.

Medical doctors with mild CVD report less difficulties in their practice than those with severe forms. ${ }^{6}$ Poole et al,${ }^{15}$ in a study on CVD among histopathologists, found that those with severe deficiency made significantly more mistakes on interpreting histopathology slides. Screening medical students offers them the possibility to become aware about CVD and to become alert during the identification of signs while examining patients or laboratory slides.

There were equal numbers of protan and deutan CVD, giving a protan:deutan ratio of 1 . A ratio of 1.1:1 was reported by Ugalahi et $\mathrm{al}^{16}$ in a study on the prevalence of CVD among secondary school students in Ibadan, South-West Nigeria. Among medical students, Pramanik et a ${ }^{17}$ found that $57.0 \%$ were protanopic, while $43.0 \%$ were deuteranopic. Other studies, however, report a higher proportion of deutans $\mathrm{s}^{6,11,12}$ or absent protanomalous deficiencies. ${ }^{18}$ Genetic variations in various populations may explain the difference.

No student with CVD in our study was aware of his deficiency. Tagarelli et al ${ }^{18}$ found that $96 \%$ of students attending middle school and $65 \%$ of students at university were not aware of their anomaly. Screening during school years would help affected students to choose their future professional orientation. Advice and support are necessary for students with CVD as awareness leads to the development of strategies to overcome this condition. Strategies to overcome difficulties described by medical doctors with CVD include paying special attention to history, close observation, or asking for help from other colleagues. ${ }^{6}$

\section{Conclusion}

The prevalence of CVD among first-cycle students of FMBS was $1.3 \%$. Although color vision screening is not a regulatory requirement, we recommend it in first-year students to raise awareness in those with CVD and to advise them accordingly. This will lead to the recognition of their limitation and avoid anxiety during training, as they will devise ways of overcoming CVDs and other such limitations.

\section{Disclosure}

The authors report no conflicts of interest in this work.

\section{References}

1. Deeb SS. Molecular genetics of color-vision deficiencies. Vis Neurosci. 2004;21(3):191-196.

2. Henry GH, Cole BL, Nathan J. The inheritance of congenital tritanopia with the report of an extensive pedigree. Ann Hum Genet. 1963;27(3): 219-231

3. Krill AE, Smith VC, Pokorny J. Further studies supporting the identity of congenital tritanopia and hereditary dominant optic atrophy. Invest Ophthalmol. 1971;10(6):457-465.

4. Birch J. Worldwide prevalence of red-green color deficiency. J Opt Soc Am A Opt Image Sci Vis. 2012;29(3):313-320.

5. Ezangono Ndo MM. Profil épidémiologique des dyschromatopsies héréditaires chez les enfants des trois écoles primaires de la ville de Douala [Epidemiological profile of congenital color vision deficiencies in children attending three primary schools in the city of Douala]. MD [Thesis]. Yaounde: University of Yaounde I; 2010. 
6. Spalding JA. Medical students and congenital colour vision deficiency: unnoticed problems and the case for screening. Occup Med. 1999; 49(4):247-252.

7. Campbell JL, Spalding JAB, Mir FA. The description of physical signs of illness in photographs by physicians with abnormal colour vision. Clin Exp Optom. 2004;87(4-5):334-338.

8. Campbell JL, Griffin L, Spalding JAB, Mir FA. The effect of abnormal colour vision on the ability to identify and outline coloured clinical signs and to count stained bacilli in sputum. Clin Exp Optom. 2005;88(6): 376-381.

9. Davison SP, Myslinski NR. Shade selection by color vision-defective dental personnel. J Prosthet Dent. 1990;63(1):97-101.

10. Dhingra R, Rohatgi J, Dhaliwal U. Preparing medical students with congenital colour vision deficiency for safe practice [Internet]. Natl Med J India [cited September 10, 2017]. Available from: http://www. nmji.in/article.asp?issn=0970-258X; year=2017; volume $=30$; issue $=1$; spage $=30$; epage $=35$; aulast=Dhingra. Accessed May 6, 2018.

11. Patel JR, Trivedi H, Patel A, Patil S, Jethva J. Assessment of colour vision deficiency in medical students. Int J Community Med Public Health. 2016;3(1):230-235.
12. Pramanik T, Khatiwada B, Pandit R. Color vision deficiency among a group of students of health sciences. Nepal Med Coll J. 2012;14(4): 334-336.

13. Vision NRC (US) C on. Color vision tests [Internet]. Washington, DC: National Academies Press (US); 1981 [cited September 15, 2017]. Available from: https://www.ncbi.nlm.nih.gov/books/NBK217823/. Accessed May 6, 2018.

14. Mughal IA, Ali L, Aziz N, Mehmood K, Azal N. Colour vision deficiency (CVD) in medical students. Pak J Physiol. 2013;9(1):14-16.

15. Poole CJ, Hill DJ, Christie JL, Birch J. Deficient colour vision and interpretation of histopathology slides: cross sectional study. BMJ. 1997; 315(7118):1279-1281.

16. Ugalahi MO, Fasina O, Ogun OA, Ajayi BG. Prevalence of congenital colour vision deficiency among secondary school students in Ibadan, South-West Nigeria. Niger Postgrad Med J. 2016;23(2):93-96.

17. Pramanik T, Sherpa MT, Shrestha R. Color vison deficiency among medical students: an unnoticed problem. Nepal Med Coll J. 2010;12(2): 81-83.

18. Tagarelli A, Piro A, Tagarelli G. Genetic, epidemiologic and social features of colour blindness. Community Genet. 1999;2(1):30-35.
Clinical Ophthalmology

\section{Publish your work in this journal}

Clinical Ophthalmology is an international, peer-reviewed journal covering all subspecialties within ophthalmology. Key topics include: Optometry; Visual science; Pharmacology and drug therapy in eye diseases; Basic Sciences; Primary and Secondary eye care; Patient Safety and Quality of Care Improvements. This journal is indexed on

\footnotetext{
Submit your manuscript here: http://www.dovepress.com/clinical-ophthalmology-journal
}

\section{Dovepress}

PubMed Central and CAS, and is the official journal of The Society of Clinical Ophthalmology (SCO). The manuscript management system is completely online and includes a very quick and fair peer-review system, which is all easy to use. Visit http://www.dovepress.com/ testimonials.php to read real quotes from published authors. 